\title{
Evaluation of pancytopenia in adults through haematological parameters and bone marrow studies
}

\author{
Pooja Agarwal ${ }^{1}$, Asbah Shams ${ }^{2}$, Prashant Prakash ${ }^{3, *}$, Harendra Kumar ${ }^{4}$, Ashwini Nigam $^{5}$ \\ 1,3,4,5 Associate Professor, ${ }^{2}$ Junior Resident, ${ }^{\mathbf{1}, 2,4}$ Dept. of Pathology, ${ }^{3,5}$ Dept. of Medicine, S.N. Medical College, Agra, \\ Uttar Pradesh, India
}

*Corresponding Author: Prashant Prakash

Email: dr.prashantprakash@gmail.com

Received: $17^{\text {th }}$ April, 2018

Accepted: $24^{\text {th }}$ April, 2018

\begin{abstract}
Introduction: Pancytopenia, simultaneous presence of anemia, leucopenia and thrombocytopenia, is a common clinical entity that we see in day to day practice Proper diagnostic evaluation requires detailed clinical history, physical examination and haematological assessment including careful peripheral blood smear examination and bone marrow evaluation.

Materials and Methods: A total of 80 adult patients with pancytopenia/bicytopenia presenting between January 2016 to January 2017 were included in the study. All patients underwent detailed clinical history and physical examination. Careful peripheral blood smear examination, $\mathrm{CBC}$ and bone marrow aspirate was done in all. Bone marrow biopsy was done wherever feasible.

Results: Megaloblastic anemia was the commonest cause of pancytopenia/bicytopenia making up 37.5\% of all cases followed by erythroid hyperplasia (20\%), aplastic anemia (10\%). Haematological malignancies accounted for $23.75 \%$ cases of the total. Bone marrow biopsy aided in the diagnosis of 8 cases ( 6 cases of aplastic anemia and two cases of dry tap) while in others it was concordant with aspiration findings.

Conclusion: Bone marrow aspiration and biopsy are an important adjunct to peripheral smear examination for evaluation of cytopenias. Bone marrow trephine biopsy is helpful in cases of dry tap. We also conclude that there is high prevalence of megaloblastic anemia due to nutritional deficiency among young population. Hence, this age range should be the prime target for education regarding proper dietary habits, the remediation of which might reduce the clinical burden of megaloblastic anemia.
\end{abstract}

Keywords: Bone marrow aspiration, Megaloblastic anemia, Pancytopenia.

\section{Introduction}

Pancytopenia, simultaneous presence of anemia, leucopenia and thrombocytopenia, is a common clinical entity that we see in day to day practice. Pancytopenia in adult is defined as haemoglobin level $<13.5 \mathrm{~g} / \mathrm{dl}$ in males and $11.5 \mathrm{~g} / \mathrm{dl}$ in females; the leucocyte count $<4$ x $10^{9} / 1$; and the platelet count $<150 \times 10^{9} / 1 .^{1}$ Bicytopenia is reduction in any of the two cell lines. The presenting symptoms are usually attributable to the anemia or the thrombocytopenia. ${ }^{1}$

A reduction in cell numbers occurs because of increased destruction, reduced production, or increased pooling in the spleen or other organs. There are various causes of pancytopenia including both neoplastic and non-neoplastic entities. Since most of the cases of pancytopenia are due to nutritional deficiencies, they are remediable and reversible. Hence, their diagnosis is of paramount importance.

Proper diagnostic evaluation requires detailed clinical history, physical examination and haematological assessment including careful peripheral blood smear examination and bone marrow evaluation. This study was undertaken to evaluate pancytopenia/bicytopenia in adult patients through haematological parameters and bone marrow studies.

\section{Materials and Methods}

All adult patients presenting with pancytopenia/bicytopenia to the Department of
Pathology in a tertiary care centre of U.P., between January 2016 to January 2017, were selected for the study. Patients on myelotoxic chemotherapy, who were unco-operative or did not give consent and in whom bone marrow examination was contra-indicated were excluded from the study. Ninety-two patients presented to us with pancytopenia/bicytopenia out of which 12 had one or the other exclusion criteria. So, finally 80 patients were included in our study. Detailed clinical history regarding generalized weakness, fever, bleeding tendencies and other symptoms was taken. Examination was done and pallor, hepato-splenomegaly, lymphadenopathy, petechiae were assessed. Blood was withdrawn in EDTA for peripheral blood smear examination and CBC, Hb, TLC, DLC, PC, MCV, MCH $\&$ MCHC were studied. Bone marrow aspiration was done subsequently using $16 \mathrm{G}$ needle and smears fixed in methylene and stained with MGG. The smears were assessed under the following headings:

1. Cellularity

2. Myeloid to Erythroid ratio

3. Erythropoiesis

4. Myelopoiesis

5. Megakaryopoiesis

6. Lymphocytes and plasma cells

7. Hemoparasites

Trephine biopsy of the bone marrow was carried out in the cases where it was required for diagnosis as in dry tap and in cases where consent was given by the patient. 
A total of 22 patients underwent bone marrow trephine biopsy. Biopsy was done from the iliac crest; posterior approach was preferred. Biopsy sections were stained with haematoxylin \& eosin. Reticulin and Perl's stain was done when indicated. Statistical analysis was done using single factor anova (analysis of variance) and pvalue $<0.01$ was considered highly significant.

\section{Results}

Most of the patients were in the age group 18-40 years and maximum cases were in the age group 20-29 years $(23.75 \%)$. Least occurrence was seen in $70-80$ years $(2.5 \%)$. The youngest patient was 18 years old and oldest was 78 years old. Most patients of megaloblastic anemia (53.3\%) were in the age group of 18-29 years.

The age distribution of the study showed that patients with pancytopenia usually present at a younger age in this geographical area. There was a male preponderance with fifty-three males and twenty-seven females. Male to female ratio was 1.94:1.

The most common presenting feature was generalized weakness $(68.75 \%)$ followed by fever (61.25\%). The commonest physical sign was pallor (100\%) followed by splenomegaly $(43.75 \%)$. Other findings were hepatomegaly (20\%), lymphadenopathy $(12.5 \%)$ and bleeding tendencies (13.75\%).

The haemoglobin values ranged from 1.4 to 10.8 $\mathrm{g} / \mathrm{dl}$. Majority of patients $(58.75 \%)$ had haemoglobin ranging from $4-7 \mathrm{~g} / \mathrm{dl}$ followed by $1-4 \mathrm{~g} / \mathrm{dl}(23.75 \%)$. $13.75 \%$ patients had haemoglobin values between 7-10 g/dl. Only $3.75 \%$ patients had haemoglobin above 10 $\mathrm{g} / \mathrm{dl}$. The leucocyte count ranged from $500-1,73,000$ cells $/ \mathrm{mm}^{3}$. Majority of the patients $(42 \%)$ had TLC values between $1000-2499$ cells $/ \mathrm{mm}^{3}$. $24 \%$ patients had TLC values between $2500-4000$ cells $/ \mathrm{mm}^{3}$. 33\% patients had values more than 4000 cells $/ \mathrm{mm}^{3}$. Only one case had TLC $<1000$ cells $/ \mathrm{mm}^{3}$. The platelet count of patients ranged from10,000 to $2,80,000$ cells $/ \mathrm{mm}^{3}$. Most of the patients $(57 \%)$ had their counts below 50,000 cells $/ \mathrm{mm}^{3}$. $28 \%$ cases had platelet count between 50,000-99,999 cells $/ \mathrm{mm}^{3}$. $11 \%$ cases had platelet counts between $1,00,000-1,50,000$ cells $/ \mathrm{mm}^{3}$. Only three patients $(4 \%)$ had platelet counts more than $1,50,000$ cells $/ \mathrm{mm}^{3}$. Platelet count higher than 50,000 cells $/ \mathrm{mm}^{3}$ was not encountered in aplastic anemia cases.

Macrocytosis was observed in majority of the cases (46\%) with MCV greater than $101 \mathrm{fl} .39 \%$ patients had MCV within normal range while $15 \%$ cases had MCV below normal. In all patients of megaloblastic anemia (37.5\%), MCV was above normal. 63\% patients had $\mathrm{MCH}$ more than the upper limit of normal while $25 \%$ cases had MCH within normal range. $12 \%$ cases had below normal $\mathrm{MCH}$. Most of the patients (43\%) had MCHC more than upper limit of normal while $31 \%$ cases had MCHC within normal range. $26 \%$ cases had below normal MCHC. (Table 1)

The most common finding on peripheral blood smear was anisocytosis seen in $94 \%$ cases followed by macrocytic blood picture (45\%). Microcytosis was noticed in $10 \%$ cases while $28 \%$ cases showed normocytic picture. $17 \%$ cases had dimorphic picture and $30 \%$ had hyper-segmented neutrophils. Hypersegmented neutrophils were seen in $80 \%$ cases of megaloblastic anemia. Circulating blasts were seen in $18.75 \%$ cases, which included 9 cases of acute leukemias and 6 cases of CML in accelerated phase. Circulating immature cells, apart from blasts, (which included myelocytes, metamyelocytes and band forms) were seen in $8.75 \%$ cases ( 6 cases of CML in accelerated phase and 1 case of megaloblastic anemia). [Table 2]

On bone marrow examination, Megaloblastic anemia was the commonest cause of pancytopenia/bicytopenia (Fig. 1). It constituted 30 out of 80 cases, making up $37.5 \%$ of all cases. Next common findings were erythroid hyperplasia (20\%) and aplastic anemia (10\%) [Fig. 2 \& 3]. Chronic myelo-proliferative neoplasms, morphologically consistent with chronic myeloid leukemia in accelerated phase, constituted 7.5\% of the total cases (Fig. 4). There were 9 cases of acute leukemias $(11.25 \%$ ) which included 5 cases of AML (6.25\%), 2 cases of ALL (2.5\%) and 2 cases of AMML (2.5\%). Other neoplastic conditions were CLL and multiple myeloma each constituting $2.5 \%$ of all cases. There were two cases of iron deficiency anemia (2.5\%). Both the cases showed absent iron stores on Perl's stain. 3 cases had normal morphology (3.75\%) and two cases yielded dry tap on aspiration. [Table 3]

Predominant PBS findings have been compared with diagnosis on bone marrow aspiration. [Table 4].

Bone marrow biopsy was performed in 22 cases. 5 cases of megaloblastic anemia, 2 cases of erythroid hyperplasia, 2 cases of multiple myeloma, 1 case of CML, 3 cases of AML and 1 case of normal marrow where biopsy was performed, the diagnosis was found to be consistent with that of aspiration. Amongst 8 cases suspicious of aplastic anemia, biopsy was performed in 6 cases. In all these cases, biopsy confirmed the diagnosis of aplastic anemia. In two cases which yielded dry tap on aspiration, biopsy was performed and reticulin stain was done. In 1 case grade 2 and in other case grade 3 fibrosis was observed which confirmed the diagnosis of myelofibrosis. (Fig. 5) Hence, the cases in which biopsy was performed, it was found to be concordant with aspiration while in 8 cases (6 cases of aplastic anemia and two cases of dry tap) it aided in the diagnosis.

The mean values of $\mathrm{Hb}$, TLC and platelet count was compared between neoplastic and non-neoplastic conditions using single factor anova (analysis of variance). The mean $\mathrm{Hb}$ of neoplastic and non-neoplastic conditions was $6.27 \mathrm{~g} / \mathrm{dl}$ and $5.17 \mathrm{~g} / \mathrm{dl}$ respectively. The mean TLC of neoplastic and non-neoplastic conditions was $611,589.5 / \mathrm{mm}^{3}$ and $3073.7 / \mathrm{mm}^{3}$ while mean platelet count was $57,736.8 / \mathrm{mm}^{3}$ and $55,967 / \mathrm{mm}^{3}$ respectively. The mean TLC value of neoplastic and non-neoplastic causes was found to be significantly different, the p-value being less than 0.01 ; while no 
statistical difference was noted between the mean values of $\mathrm{Hb}$ and platelet count.

The mean values of $\mathrm{Hb}$, TLC and platelet count was compared between megaloblastic anemia, erythoid hyperplasia, aplastic anemia and haematological malignancies using single factor anova. The mean values for haemoglobin and TLC of all the above listed conditions, showed significant difference when compared with each other, ( $\mathrm{p}$-value $<0.01 \%$ ). Mean value of platelet count was not statistically significant between these conditions. [Table 5]

Serum vitamin B12 and Folic acid levels were done in 19 out of 30 cases of megaloblastic anemia (11 cases were lost on follow up) by Chemiluminescent Immunoassay on Advia Centaur CP. The reference value for vitamin B12 was between 211-946 pg/ml. For folic acid assay, levels $>5.38 \mathrm{ng} / \mathrm{ml}$ were considered normal, between $3.38-5.38 \mathrm{ng} / \mathrm{ml}$ were considered indeterminate and values between $0.35-3.37 \mathrm{ng} / \mathrm{ml}$ were considered deficient. All patients showed vitamin B12 levels less than $211 \mathrm{pg} / \mathrm{ml}$. 5 cases showed normal folic acid levels $(>5.38 \mathrm{ng} / \mathrm{mg}), 11$ patients showed values between $3.38-5.38 \mathrm{ng} / \mathrm{ml}$, while only two cases of megaloblastic anemia showed folate level below $3.37 \mathrm{ng} / \mathrm{ml}$. Hence, out of 19 cases of megaloblastic anemia evaluated serologically, 17 cases showed vitamin B12 deficiency and two cases showed combined vitamin B12 and folate deficiency.

\section{Discussion}

In our study of 80 cases, 52 cases (65\%) presented with pancytopenia and 28 cases $(35 \%)$ presented with bicytopenia.

In our study, male to female ratio was 1.94: 1 and the age range was between $18-80$ years. The most common age group was 20-29 years. 53.3\% patients of megaloblastic anemia were in the age group 18-29 years. This highlights the high prevalence of nutritional deficiency in young population. Dietary restriction owing to low socio-economic status or consumption of nutrition-poor hostel food, dieting for weight loss or intake of supplements instead of proper food by gym goers seem the probable explanation for this finding.

Chandra $\mathrm{K}$ et $\mathrm{al}^{2}$ and Javalgi AP et $\mathrm{al}^{3}$ also reported male predominance and similar age group in their studies. Desalphine $\mathrm{M}$ et $\mathrm{al}^{4}$ observed male to female ratio of 1.8:1 and age range of 5-80 years. The findings of their studies are slightly different from our study, as they included pediatric patients in their study, while our study comprised of adult population only.

The most common presenting feature in patients with pancytopenia/bicytopenia in our study was generalized weakness $(68.75 \%)$ followed by fever (61.25\%). Gayathri BN et $\mathrm{al}^{5}$ and Thakkar BB et al ${ }^{6}$ also observed generalised weakness as the most common presenting symptom in $100 \% \& 97 \%$ cases respectively. The commonest physical sign was pallor seen in $100 \%$ cases. Khodke K et al, ${ }^{7}$ Tilak V et al, ${ }^{8}$ Ishtiaq $\mathrm{O}$ et al, ${ }^{9}$
Gayathri BN et al, ${ }^{5}$ Thakkar BB et al, ${ }^{6}$ Chandra $\mathrm{K}$ et al ${ }^{2}$ also reported pallor in $100 \%$ of the cases, which is consistent with our finding.

In our study, splenomegaly was seen in $43.75 \%$ cases. Kumar DB et al, ${ }^{10}$ Chandra $\mathrm{K}$ et $\mathrm{al}^{2}$ and Sweta $\mathrm{S}$ et $\mathrm{al}^{11}$ reported splenomegaly in $33.33 \%, 33.73 \%$ and $33 \%$ cases respectively. A slightly higher incidence of splenomegaly in our study could be because we encountered six patients of chronic myelo-proliferative neoplasm, morphologically consistent with chronic myeloid leukemia in accelerated phase, while CML cases were not reported in previous studies. Splenomegaly is a common finding in CML.

The most common finding on peripheral blood smear was anisocytosis seen in $94 \%$ cases. Khodke K et al,${ }^{7}$ Tilak V et al, ${ }^{8}$ Gayathri BN et $\mathrm{al}^{5}$ and Kumar DB et $\mathrm{al}^{10}$ also reported anisocytosis to be the commonest finding on peripheral blood smear, their values being $60 \%, 83.1 \%, 86.5 \%$ and $79.1 \%$ respectively. This is consistent with the finding in our study. Macrocytosis in our study was noted in $45 \%$ cases which is consistent with Sweta $\mathrm{S}$ et $\mathrm{al}^{11}$ and Ishtiaq $\mathrm{O}$ et $\mathrm{al}^{9}$ who reported macrocytosis in $49 \%$ and $55 \%$ cases respectively. Microcytosis was seen in $10 \%$ cases in our study. Ishtiaq $\mathrm{O}$ et $\mathrm{al}^{9}$ reported microcytic anemia in $12 \%$ cases, which is concordant with our study. Dimorphic blood picture was seen in $17 \%$ cases in our study. Gayathri BN et al ${ }^{5}$ reported dimorphic anemia in $37.5 \%$ cases which is slightly higher than in our study.In our study, $30 \%$ cases

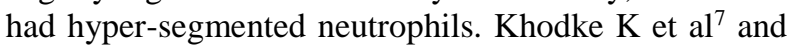
Ishtiaq $\mathrm{O}$ et $\mathrm{al}^{9}$ reported hypersegmented neutrophils in $40 \%$ and $36 \%$ cases respectively. Their findings are similar to the findings in our study. This could be because they also reported megaloblastic anemia as the commonest cause of pancytopenia/bicytopenia. Kumar DB et $\mathrm{al}^{10}$ however, reported hypersegmented neutrophils in $14.58 \%$ cases which is lower than that in our study. This could be because they reported hypoplastic marrow as the commonest cause of pancytopenia. In a well preserved PBS, neutrophil hypersegmentation can be defined as the presence of neutrophils with six or more lobes or the presence of more than $3 \%$ of neutrophils with at least five lobes. However, apart from megaloblastic anemia, hypersegmented neutrophils are also seen in uremia, iron deficiency anemia, after cytotoxic chemotherapy especially with methotrexate.

The most common cause of pancytopenia/bicytopenia in our study was megaloblastic anemia seen in 30 cases, making up 37.5\% of all cases. This is consistent with the results of Khodke $\mathrm{K}$ et al, ${ }^{7}$ Tilak V et al, ${ }^{8}$ Ishtiaq $\mathrm{O}$ et al, ${ }^{9}$ Gayathri BN et $\mathrm{al}^{5}$ and Sweta $\mathrm{S}$ et $\mathrm{al}^{11}$ who also reported megaloblastic anemiaas the commonest cause of pancytopenia/bicytopenia in their studies.

The second most common finding in our study was erythroid hyperplasia, which was seen in 16 cases making up 20\% of total. Erythroid hyperplasia, although 
is not a cause of pancytopenia, but came out to be the $2^{\text {nd }}$ most common finding in our study, as also reported by other authors. ${ }^{4}{ }^{10}$ Some of these cases had macrocytosis in PBS which probably reflects that they were cases of megaloblastic anemia, in whom therapy had been initiated.

Aplastic anemia/hypoplasticanemia was observed in 8 cases $(10 \%)$. This was in stark contrast to Kumar R et $\mathrm{al}^{12}$ who reported aplastic anemia as the commonest cause in a series of 166 cases in age group 12-73 years. Desalphine $\mathrm{M}$ et $\mathrm{al}^{4}$ studied 50 cases of pancytopenia, including pediatric population and their most common etiology was aplastic anemia followed by erythroid hyperplasia. A higher incidence of aplastic anemia in their study could be because they included pediatric subjects and aplastic anemias are a common cause of pancytopenia in children.

Another major entity in our study was that of hematologic malignancies seen in 19 cases and making up $23.75 \%$ of all cases. Chandra $\mathrm{K}$ et $\mathrm{al}^{2}$ studied 83 cases of pancytopenia and reported acute leukemia (15.67\%) as the second most common etiology after megaloblastic anemia. Desalphine $\mathrm{M}$ et $\mathrm{al}^{4}$ also reported $14 \%$ cases of subleukemicleukemias. Our study showed a slightly higher, though comparable, incidence of acute leukemia.

Most of the patients $(46 \%)$ had MCV greater than $101 \mathrm{fl} /$ cell. MCV within normal range was seen in $39 \%$ patients while $15 \%$ cases had MCV below normal. In all patients of megaloblastic anemia, MCV was above normal. In study by Sweta $\mathrm{S}$ et al, ${ }^{11}$ similar findings were reported with high MCV in $49 \%$ cases, normal in $44 \%$ cases and decreased in $7 \%$ cases.

On bone marrow aspiration, majority of the smears were hypercellular $(78.75 \%)$. Normocellular marrow was seen in $8.75 \%$ cases while $10 \%$ cases had hypocellular marrow. In two cases $(2.5 \%)$, a dry tap was obtained so cellularity could not be assessed. The principal causes of pancytopenia in our study were megaloblastic anemia, erythroid hyperplasia and haematological malignancies in which marrow cellularity is mostly increased. This finding is consistent with previous studies of Chandra $\mathrm{K}$ et $\mathrm{al}^{2}$ and. Sweta $\mathrm{S}$ et $\mathrm{al}^{11}$ who reported hypercellular marrow in $68.7 \%$ and $72 \%$ cases respectively.

In our study, serum vitamin B12 and Folic acid levels were done in 19 out of 30 cases of megaloblastic anemia (11 cases were lost on follow up). Out of 19 cases, 17 cases showed vitamin B12 deficiency and two cases showed combined vitamin B12 and folate deficiency. Our findings are similar to the findings of a previous study done by Khanduri $\mathrm{U}$ et al. ${ }^{13}$ In their study of 120 patients of megaloblastic anemia, who had assays done for cobalamin and folate, $65 \%$ had cobalamin deficiency, $6 \%$ had folate deficiency and $12 \%$ had combined deficiency.

Table 1: MCV, MCH \& MCHC findings in patients of pancytopenia/bicytopenia

\begin{tabular}{|l|c|c|c|c|}
\hline & Normal & Below normal & Above normal & Total \\
\hline $\mathrm{MCV}$ & $39 \%$ & $15 \%$ & $46 \%$ & $100 \%$ \\
\hline $\mathrm{MCH}$ & $25 \%$ & $12 \%$ & $63 \%$ & $100 \%$ \\
\hline $\mathrm{MCHC}$ & $31 \%$ & $26 \%$ & $43 \%$ & $100 \%$ \\
\hline
\end{tabular}

Table 2: Peripheral blood smear findings

\begin{tabular}{|l|c|c|}
\hline PBS findings & No. of cases (out of 80) & Percentage (in \%) \\
\hline Normocytic & 22 & $28 \%$ \\
\hline Macrocytic & 36 & $45 \%$ \\
\hline Microcytic & 08 & $10 \%$ \\
\hline Dimorphic picture & 14 & $17 \%$ \\
\hline Anisocytosis & 75 & $94 \%$ \\
\hline Hypersegmented neutrophils & 24 & $30 \%$ \\
\hline Circulating blasts & 15 & $18.75 \%$ \\
\hline Circulating immature cells (apart from blasts) & 7 & $8.75 \%$ \\
\hline
\end{tabular}

Table 3: Findings on bone marrow aspiration

\begin{tabular}{|l|c|c|}
\hline Final diagnosis & No. of cases & Percentage (in \%) \\
\hline Megaloblastic Anemia & 30 & $37.5 \%$ \\
\hline Erythroid Hyperplasia & 16 & $20 \%$ \\
\hline Aplastic Anemia & 08 & $10 \%$ \\
\hline CMPN, consistent with CML & 06 & $7.5 \%$ \\
\hline AML & 05 & $6.25 \%$ \\
\hline AMML & 02 & $2.5 \%$ \\
\hline ALL & 02 & $2.5 \%$ \\
\hline Normal marrow & 03 & $3.75 \%$ \\
\hline
\end{tabular}




\begin{tabular}{|l|c|c|}
\hline Iron deficiency anemia & 02 & $2.5 \%$ \\
\hline CLL & 02 & $2.5 \%$ \\
\hline Multiple Myeloma & 02 & $2.5 \%$ \\
\hline Dry tap & 02 & $2.5 \%$ \\
\hline Grand Total & $\mathbf{8 0}$ & $\mathbf{1 0 0 \%}$ \\
\hline
\end{tabular}

Table 4: Correlation of PBS findings with diagnosis on bone marrow aspiration

\begin{tabular}{|l|c|}
\hline \multicolumn{1}{|c|}{ PBS findings } & Diagnosis on BMA \\
\hline Anisocytosis & All cases \\
\hline Macrocytic picture & Megaloblastic anemia Aplastic anemia \\
\hline Hypersegmented neutrophils & Megaloblastic anemia \\
\hline Microcytic & Erythroid hyperplasia, Iron deficiency anemia \\
\hline Normocytic & Erythroid hyperplasia \\
& Hematologic malignancies \\
\hline Dimorphic picture & Aplastic anemia \\
\hline Circulating blasts & AML, ALL, AMML \\
\hline Circulating immature cells (apart from blasts) & CML \\
\hline Leucoerythroblastosis, tear drop cells & Dry tap \\
\hline
\end{tabular}

Table 5: Comparison of haematological parameters between the four common causes of pancytopenia/bicytopenia in our study

\begin{tabular}{|c|c|c|c|c|c|}
\hline \multirow[t]{2}{*}{ Parameters } & \multirow[t]{2}{*}{ Range/Mean } & $\begin{array}{l}\text { Megaloblastic } \\
\text { anemia }\end{array}$ & \multirow[t]{2}{*}{$\begin{array}{c}\text { Aplastic } \\
\text { anemia }(8 / 80)\end{array}$} & $\begin{array}{c}\text { Erythroid } \\
\text { hyperplasia }\end{array}$ & $\begin{array}{l}\text { Hematologic } \\
\text { malignancies }\end{array}$ \\
\hline & & $(30 / 80)$ & & $(16 / 80)$ & $(19 / 80)$ \\
\hline \multirow[t]{2}{*}{$\mathrm{Hb}(\mathrm{g} / \mathrm{dl})$} & Range & $1.4-8.7$ & $2.6-7.8$ & $2.1-10.8$ & $3.5-8.9$ \\
\hline & Mean & 4.41 & 5 & 6.05 & 6.27 \\
\hline \multirow{2}{*}{$\begin{array}{l}\text { TLC } \\
\left(\text { cells } / \mathrm{mm}^{3}\right)\end{array}$} & Range & $500-7,600$ & $1200-2600$ & $1000-12,300$ & $1800-1,73,000$ \\
\hline & Mean & 3218.5 & 2050 & 2914.3 & $61,589.50$ \\
\hline \multirow{3}{*}{$\begin{array}{l}\text { Platelet count } \\
\text { (cells/mm3) }\end{array}$} & Range & $10,000-1,40,000$ & $16,000-40,000$ & $20,000-1,60,000$ & $11,000-1,40,000$ \\
\hline & Mean & 50,889 & 27,000 & 57,071 & $57,736.80$ \\
\hline & & & & & \\
\hline
\end{tabular}

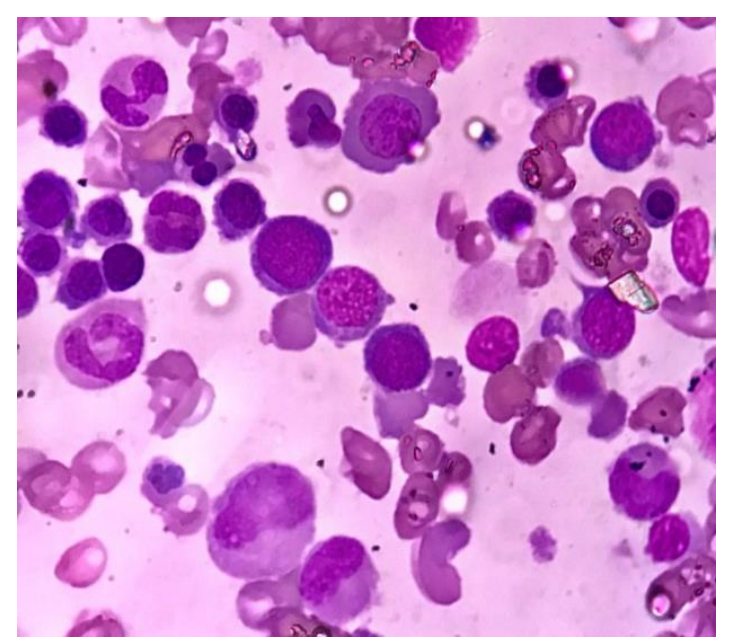

Fig. 1: Bone marrow aspirate from a patient of megaloblastic anaemia.(MGG 100x)

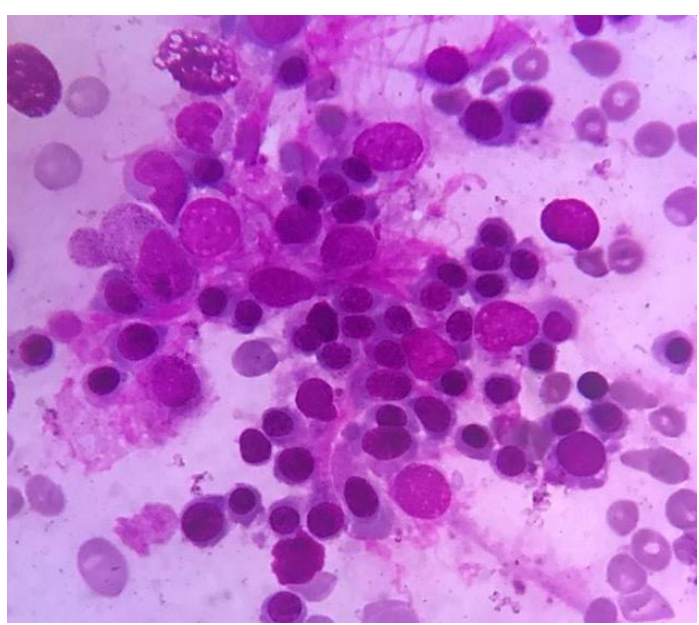

Fig. 2: Bone marrow aspirate smear showing normoblastic erythroid hyperplasia (MGG 40x) 


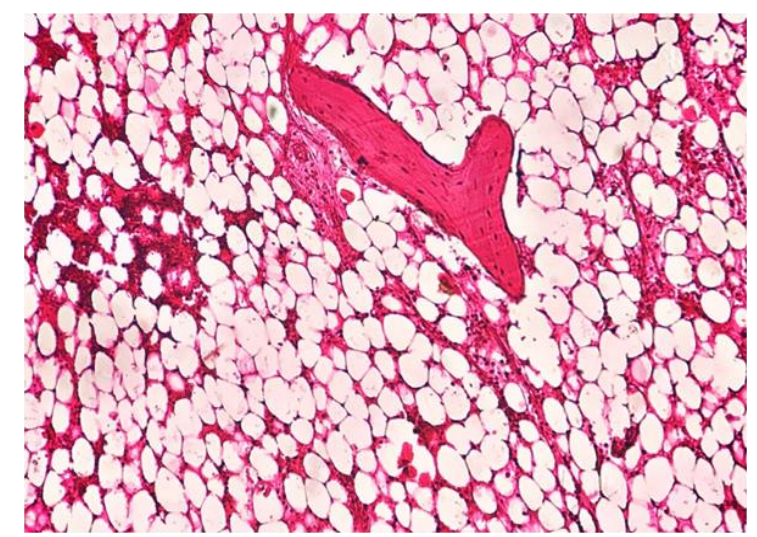

Fig. 3: Bone marrow biopsy in a case of aplastic anemia showing paucity of hematopoietic cells and marrow space largely replaced by fat. (H\&E 40x)

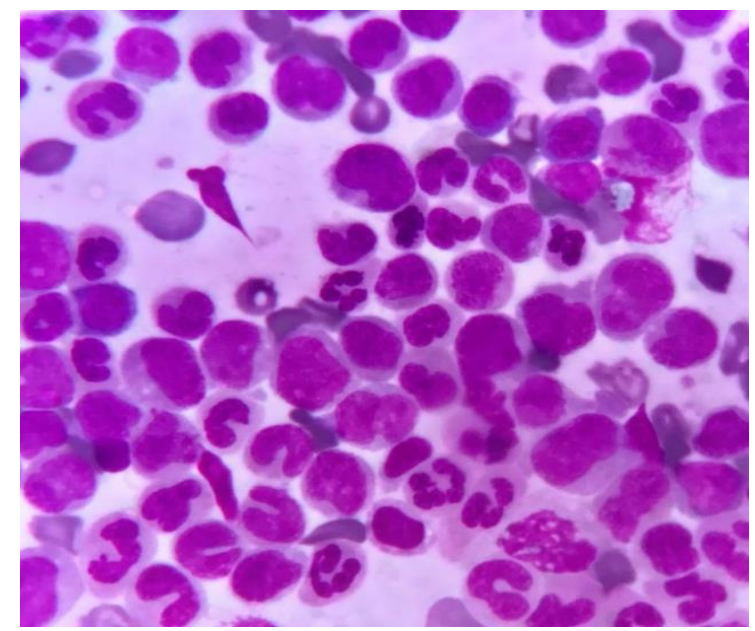

Fig. 4: Bone marrow aspirate showing neutrophils and blasts in a case of CML in accelerated phase. (MGG 100x)

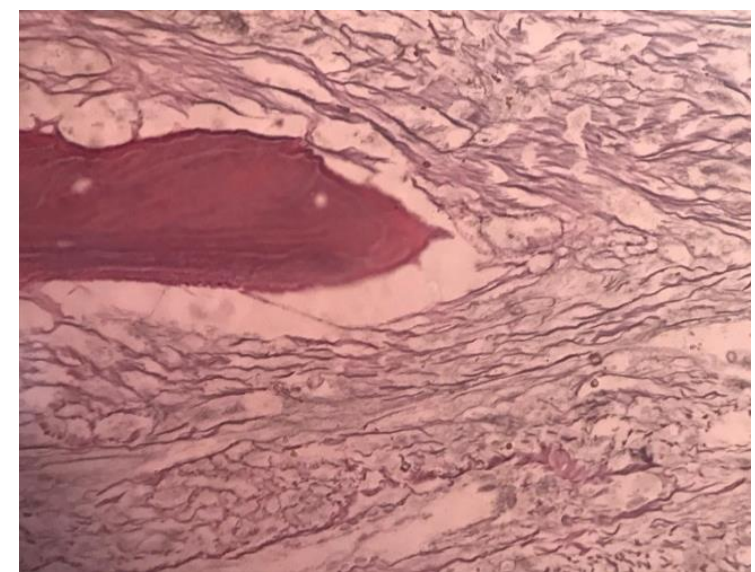

Fig. 5: Bone marrow biopsy showing grade 3 reticulin fibres in a case of myelofibrosis (Reticulin stain 40x)

\section{Conclusion}

We hereby conclude that bone marrow aspiration and biopsy are an important adjunct to peripheral smear examination for evaluation of cytopenias. Bone marrow aspirate is superior to study the morphology, however, a 'dry' or 'blood tap' is common in disorders causing pancytopenia. Hence, trephine biopsy is needed in these cases for diagnosis. Through our study, we also conclude that there is high prevalence of nutritional deficiency among young population and we have also listed the probable reasons for the same. Hence, this age range should be the prime target for education regarding proper dietary habits, the remediation of which might reduce the clinical burden of megaloblastic anemia.

\section{References}

1. Mahapatra M. Pancytopenia; Aplastic anemia. In: Saxena R, Pati HP, Mahapatra M, editors.de Gruchy's Clinical Hematology in Medical Practice, $6^{\text {th }}$ ed. New Delhi: Wiley;2013:106.

2. Chandra K, Kumar P. Morphological Spectrum of Bone Marrow in Pancytopenia - a retrospective study in a Tertiary Care Centre. JEMDS. 2014;3(4):1056-1064

3. Javalgi AP, Dombale VD. Clinico - Hematological Analysis of Pancytopenia: A Bone Marrow Study. NJLM. 2013;2(4):12-17.

4. Desalphine M, Bagga PK, Gupta PK, Kataria AS. To Evaluate the Role of Bone Marrow Aspiration and Bone Marrow Biopsy in Pancytopenia. JCDR. 2014;8(11):1115.

5. Gayathri BN, Rao KS. Pancytopenia: A Clinicohematological study. J Lab Physicians. 2011;3(1):15-20.

6. Thakkar BB, Bhavsar UN, Trivedi NJ, Agnihotri AS. A Study of Pancytopenia in Adult patients more than 12 years of age in North West region of Saurashtra. NJMR 2013; 3(1):48-52.

7. Khodke K, Marwah S, Buxi G, Yadav RB, Chaturvedi NK. Bone Marrow Examination in cases of pancytopenia. J Academy Clin Med. 2001;2(1,2):55-59.

8. Tilak V, Jain R. Pancytopenia-A Clinco-hematologic analysis of 77 cases. Indian J Pathol Microbiol. 1999;42(4):399-404.

9. Ishtiaq O, Baqai HZ, Anwer F, Hussain N. Patterns of Pancytopenia Patients in a General Medical Ward and a Proposed Diagnostic Approach. Available from: http://www.ayubmed.edu.pk/JAMC/PAST/161/osama.htm-206K-6/24/2007.

10. Kumar DB, Raghupathi AR. Clinicohematologic Analysis of Pancytopenia: Study in a Tertiary Care Centre. Basic and Applied Pathology. 2012;5(1):19-21.

11. Sweta S, Barik S, Chandoke RK, Verma AK. A Prospective Clinico-hematological study in 100 cases of Pancytopenia in capital city of India. J Appl Hematol. 2014;5(2):45-50.

12. Kumar R, Kalra SP, Kumar H, Anand AC, Madan H. Pancytopenia-A six year study. J Assoc Physicians India. 2001;49:1078-81.

13. Khanduri U, Sharma A. Megaloblastic anaemia: Prevalence and causative factors. Natl Med J India. 2007;20(4):172-175.

How to cite this article: Agarwal P, Shams A,
Prakash P, Kumar H, Nigam A. Evaluation of
pancytopenia in adults through haematological
parameters and bone marrow studies. Indian J Pathol
Oncol. 2018;5(4):548-553.

